\title{
Advancing the Water Footprint into an Instrument to Support Achieving the SDGs - Recommendations from the "Water as a Global Resources" Research Initiative (GRoW)
}

\author{
Markus Berger $^{1}$ (D) Jazmin Campos $^{2} \cdot$ Mauro Carolli $^{3} \cdot$ Ianna Dantas ${ }^{4} \cdot$ Silvia Forin $^{1}$. \\ Ervin Kosatica ${ }^{5} \cdot$ Annika Kramer $^{6}$ - Natalia Mikosch ${ }^{1} \cdot$ Hamideh Nouri $^{7}$. \\ Anna Schlattmann ${ }^{8} \cdot$ Falk Schmidt $^{9} \cdot$ Anna Schomberg $^{10} \cdot$ Elsa Semmling $^{6}$
}

Received: 22 July 2020 / Accepted: 26 January 2021 /

Published online: 4 March 2021

(C) The Author(s) 2021

\begin{abstract}
The water footprint has developed into a widely-used concept to examine water use and resulting local impacts caused during agricultural and industrial production. Building on recent advancements in the water footprint concept, it can be an effective steering instrument to support, inter alia, achieving sustainable development goals (SDGs) - SDG 6 in particular. Within the research program "Water as a Global Resource" (GRoW), an initiative of the Federal Ministry for Education and Research, a number of research projects currently apply and enhance the water footprint concept in order to identify areas where water is being used inefficiently and implement practical optimization measures (see imprint for more information). With this paper, we aim to raise awareness on the potential of the water footprint concept to inform decision-making in the public and private sectors towards improved water management and achieving the SDGs.
\end{abstract}

Keywords Water footprint $\cdot$ Sustainable development goals

Markus Berger

markus.berger@tu-berlin.de

1 Chair of Sustainable Engineering, Technische Universität Berlin, Berlin, Germany

2 Institute for Environment and Human Security (UNU-EHS), United Nations University (UNU), Bonn, Germany

3 Dept. 2 Ecosystem Research, Leibniz-Institute Für Gewässerökologie Und Binnenfischerei, Berlin, Germany

$4 \quad$ Kiel Institute for the World Economy, Kiel, Germany

5 Professorship of Ecological Services, University of Bayreuth, Bayreuth, Germany

6 adelphi, Berlin, Germany

7 Division of Agronomy, University of Göttingen, Göttingen, Germany

8 Institute of Environmental Planning, Leibniz Universität Hannover, Hanover, Germany

9 Institute for Advanced Sustainability Studies, Potsdam, Germany

10 University of Kassel, Center for Environmental Systems Research, Kassel, Germany 


\section{Development of the Water Footprint - from Global Volumes to Local Impacts}

Two billion people live in countries experiencing high water stress, and more than four billion lack access to basic sanitation (UN Water 2019). The "water crisis" is constantly ranked among the top 5 global risks reported by the World Economic Forum in its annual global risk reports (WEF 2020). The link between the global water crisis and our production and consumption of water intense products has been made transparent by concepts like "Virtual Water". This concept denotes the volumes of water used in the production of goods and services, differentiating the consumption of ground and surface water (blue water), soil moisture (green water), and the pollution of freshwater (gray water). By revealing surprisingly high volumes, like $140 \mathrm{~L}$ per cup of coffee (Chapagain and Hoekstra 2007), up to 15,500 L per kilogram of beef (Hoekstra and Chapagain 2007) or 2,700 L per cotton T-shirt (Chapagain et al. 2006), consumers have been made aware of the high "water footprints" (WF) of daily goods. Despite the relevance of global freshwater appropriation figures for awareness raising and analyzes of virtual water trade via imports and exports of products, such volumetric approaches have been criticized for the lack of environmental and socio-economic meaning (Ridoutt and Huang 2012). For instance, the local consequences of consuming $1 \mathrm{~m}^{3}$ of rainwater in Sweden do not compare to those resulting from the consumption of $1 \mathrm{~m}^{3}$ of groundwater in Egypt.

In order to add this local component to the WF concept, methods assessing local consequences resulting from water use have been developed within the scope of life cycle assessment (Berger and Finkbeiner 2010). Some of those impact assessment methods estimate the local consequences of water consumption based on freshwater scarcity (Pfister et al. 2009; Boulay et al. 2018; Berger et al. 2018). Other methods allow to assess the effects of water consumption on:

- human health and well-being (due to malnutrition Pfister et al. 2009; Boulay et al. 2011; Motoshita et al. 2018) or infectious diseases (Boulay et al. 2011; Motoshita et al. 2011))

- ecosystems (terrestrial Pfister et al. 2009; van Zelm et al. 2011; Lathuillière et al. 2016), aquatic (Hanafiah et al. 2011; Damiani et al. 2018), coastal (Amores et al. 2013), wetlands (Verones et al. 2013), urban (Nouri et al. 2019a))

- freshwater resources (Mila i Canals et al. 2008; Pfister et al. 2009; Pradinaud et al. 2019)

The scientific advancement of the WF concept and relevance of global freshwater use has led to the development of an international WF standard (ISO 14,046) which specifies principles, requirements and guidelines related to WF analyses of products, processes and organizations (ISO 14046 2014).

\section{The "Water as a Global Resource" Research Initiative}

In one of the largest contemporary research initiatives on "Water as a Global Resource" (GRoW 2020), funded by the German Ministry of Education and Research), approximately 300 researchers, practitioners and stakeholders around the world are developing new approaches for improving management and governance in the water sector. Within this initiative, seven research projects currently apply and enhance the water footprint concept in order to identify areas where water is being used inefficiently and implement practical optimization measures. With this short communication, we aim to raise awareness on the 
potential of the water footprint concept to inform decision-making in the public and private sectors towards improved water management and achieving the SDGs-SDG 6 in particular.

\section{The Water Footprint-Opportunities for Achieving SDGs}

Building on the advancement of the WF concept within the last 20 years, WF assessments today can support different stakeholders in achieving the SDGs, and in particular SDG 6, in the areas policy and planning, production and consumers.

\subsection{Policy and Planning}

Modern WF methods and tools can inform policy decisions towards more sustainable use of water resources at various levels.

As water intense products are shipped around the globe, water associated with their production is virtually traded between world regions, e.g. from developing countries into the European Union via cotton and textiles or mineral resources used for conventional and renewable energy production. An analysis of this virtual water trade can reveal the volumes of water associated with trade and resulting impacts in the exporting countries (Dolganova et al. 2019; Koellner et al. 2019). It can also show the extent to which water scarcity in a country is caused by its export of water intense goods. Thus, taking a global perspective, analyzing the WF and virtual water trade can inform national strategies and trade decisions. This is illustrated for crop imports and exports to and from Israel and the associated trade of virtual water and ecosystem services in the GRoW research project MedWater (2020).

On a national or regional level, assessing the WF of agricultural production, energy generation and water intense industries can guide sectoral policies and planning. It can e.g. inform land-use planning by identifying areas where production is associated with high impacts on land and water resources, ecosystems and human health. The GRoW research project go-CAM (2020) uses WF calculations as additional information for a Multi Criteria Decision Analysis to support decision making on water management strategies in the water stressed region of Northwest Germany.

The WF can also be applied to identify trade-offs and synergies between strategies to achieve water security (SDG6), energy security (SDG7) and food security (SDG2) - also known as the Water-Food-Energy Security Nexus (Hoff 2011) —which is of high relevance as the SDGs are strongly interrelated and can only be achieved in relation to one another. As the 2030 Agenda is an agenda of transformation (WBGU - German Advisory Council on Global Change 2011), WF is a key concept to guide water-related transformation processes effectively.

On a more local level, the WF concept can inform policy decisions on how to achieve water-use efficiency e.g. by demonstrating how improved use of green water can help to reduce water scarcity (Schyns et al. 2019). This might imply accepting lower yields for saving blue water resources, or deciding to import water intense products rather than producing them domestically. 


\subsection{Producers}

Modern WF methods and tools can support producers in determining their indirect water use and associated impacts in supply chains in addition to their (often comparably low) direct water use at production sites. Producers can use this knowledge to:

Design products in a way which reduces the indirect water use in supply chains by e.g. substituting water intense materials or using secondary materials.

Broaden corporate environmental strategies, which usually focus on site-specific water reduction targets. It can be economically more efficient and environmentally more beneficial to save water at water hotspots in supply chains.

Support sustainable procurement by identifying where water efficient raw materials and intermediate products could be part of a company's environmental management strategy. The GRoW project WELLE (2020) has developed an online tool (http://wf-tools.see.tuberlin.de) enabling companies to determine water consumption along all stages of global supply chains and to reduce their water footprint at local hotspots.

Reduce water risks by identifying local hotspots in global supply chains to design appropriate measures in cooperation with suppliers and local stakeholders, e.g. through water stewardship approaches.

Promote more sustainable agricultural management practices, e.g. changing crops or growing seasons to make better use of available green water resources, thereby alleviating the WF in agriculture and increasing the nutritional and economic water productivity (Nouri et al. 2019b, 2020).

Identify potential hotspots of water scarcity in modern electricity production supply chains, e.g. concentrated solar power, with a special focus on remote impacts induced by mining of mineral resources that are required in electricity generation. The GRoW project WANDEL (2020) analyzes if restrictions on water availability for energy systems can accelerate or decelerate the global energy transition.

\subsection{Consumers}

The WF can raise awareness and inform consumers about the hidden water use and resulting impacts of daily products and services. Based on this information, unsustainable consumption of water intense products (e.g. fast fashion) or waste of water intense goods (e.g. food) can be identified and subsequently reduced. This can contribute to incentivising agriculture and industry to produce water efficient products-helping to achieve SDG 6, but also improving sustainable consumption addressed under SDG 12. The GRoW project InoCottonGROW (2020) developed a framework to communicate the WF of textiles to consumers by means of ecolabels considering best water management practice in cotton cultivation and textile production.

\section{Methodological and Practical Challenges}

Despite the scientific advancement of the WF concept, several challenges remain that may hamper its wider application as an instrument to guide decision-making towards more sustainable water use. The GRoW Program and other research initiatives currently develop innovative approaches to address these challenges. 
While several methodologies have been developed that allow evaluating the impacts of water use, most WF studies stay on a volumetric level and do not consider consequences of water use, such as impacts on human health, biodiversity or ecosystem services. The GRoW project ViWA (2020) includes biodiversity into a refined water scarcity assessment in order to support decision making towards environmentally sustainable water use.

Methodologies to assess impacts of water use on water quality have not yet been sufficiently developed. Impacts on water quality are often not addressed or only calculated based on a single quality parameter. The GRoW project InoCottonGROW (2020) analyzes local cause-effect chains of water pollution resulting from the use of pesticides in cotton cultivation and the emission of hazardous substances in textile dying in Pakistan.

Most studies merely focus on the blue water scarcity and blue water saving. However, using limited green water resources efficiently seems equally important, especially when addressing questions related to water scarcity, food security, and water saving potentials (Schyns et al. 2019; Hoekstra 2019). This requires assessing the green water footprint.

Comparing and linking assessments conducted at different geographical levels or spatial scales is a major challenge. Global models with high uncertainty can be used for identifying potential hotspots - however, local models with high complexity are more reliable to quantify local impacts (Mikosch et al. 2020), despite being difficult to upscale. Moreover, missing inventory data and weak data quality are sometimes leading to limited robustness of WF results and comparability.

Studies analyzing the virtual water trade between countries (e.g. Hoekstra and Hung 2002; Hoekstra and Mekonnen 2012; Suweis et al. 2013) are often followed by rather narrowly focused recommendations, such as moving production sites to water abundant regions or putting taxes on water intense goods imported from water scarce countries (Hoekstra 2013). However, such suggestions are often heavily criticized for causing economic damages in developing countries (Gawel and Bernsen 2013; Wichelns 2015).

While the growing number of WF methods developed increases the knowledge on products' water use and a variety of associated impacts, it becomes increasingly difficult for practitioners to choose the most adequate method for the question to be answered. For this reason, the GRoW community developed an online-toolkit (https://wf-tools.see.tu-berli n.de/wf-tools/waterfootprint-toolbox/) which guides users to the most suitable method depending on the question to be answered when undertaking a water footprint assessment.

\section{Conclusions and Recommendation}

Based on the findings of the seven GRoW research project working on the WF concept and the discussions within a cross-cutting working group, we recommend to:

Take a holistic perspective on the water footprint: In order to make meaningful use of the WF concept as a steering instrument to guide decision making at various levels, the impacts of water use need to be assessed in addition to liters of water consumed. The GRoW community recommends applying recently developed methods to assess local impacts resulting from both water consumption and water pollution.

Make use of the water footprint to identify where investment in more sustainable water use is most efficient. For private companies as well as for governments, it might be environmentally more beneficial and often economically more efficient and to invest in water use efficiency measures at suppliers or in exporting countries 
which face high water stress rather than focusing on production-site or domestic measures only.

Analyse virtual water flows and resulting impacts in order to identify hotspots, for instance associated with European imports, and develop specific policy measures mitigating local water stress in the exporting countries. These could include providing incentives for more efficient water usage or steering specific technical development assistance. Policy measures based on virtual water trade analysis should consider local circumstances to prevent negative social and economic trade-offs, such as, reduced income or unemployment.

Apply the water footprint to guide decisions on strategies to achieve SDGs interlinked with SDG 6 on water. Measures and strategies to achieve SDGs, especially those related to energy (SDG7), food security (SDG2), but also climate change (SDG 12) and sustainable consumption and production (SDG 12) can have positive or negative impacts on water resources. The WF is a useful instrument to assess and consequently address such interlinkages.

Funding Open Access funding enabled and organized by Projekt DEAL. This paper was developed in the context of the funding measure "Water as a Global Resource" (GRoW), funded by the Federal Ministry of Education and Research (BMBF), Germany.

\section{Declarations}

\section{Conflict of Interest None.}

Open Access This article is licensed under a Creative Commons Attribution 4.0 International License, which permits use, sharing, adaptation, distribution and reproduction in any medium or format, as long as you give appropriate credit to the original author(s) and the source, provide a link to the Creative Commons licence, and indicate if changes were made. The images or other third party material in this article are included in the article's Creative Commons licence, unless indicated otherwise in a credit line to the material. If material is not included in the article's Creative Commons licence and your intended use is not permitted by statutory regulation or exceeds the permitted use, you will need to obtain permission directly from the copyright holder. To view a copy of this licence, visit http://creativecommons.org/licenses/by/4.0/.

\section{References}

Amores MJ, Verones F, Raptis C et al (2013) Biodiversity impacts from salinity increase in a Coastal Wetland. Environ Sci Technol 47:6384-6392

Berger M, Finkbeiner M (2010) Water footprinting - how to address water use in life cycle assessment? Sustainability 2:919-944

Berger M, Eisner S, van der Ent R et al (2018) Enhancing the water accounting and vulnerability evaluation model: WAVE+. Environ SciTechnol 52:10757-10766

Boulay A-M, Bulle C, Bayart J-B et al (2011) Regional characterization of freshwater use in LCA: modelling direct impacts on human health. Environ SciTechnol 45:8948-8957

Boulay A-M, Bare J, Benini L et al (2018) The WULCA consensus characterization model for water scarcity footprints: assessing impacts of water consumption based on available water remaining (AWARE). Int J Life Cycle Assess 23:368-378

Chapagain AK, Hoekstra AY (2007) The water footprint of coffee and tea consumption in the Netherlands. Ecol Econ 1:109-118

Chapagain AK, Hoekstra AY, Savenije HHG, Gautam R (2006) The water footprint of cotton consumption: an assessment of the impact of worldwide consumption of cotton products on the water resources in the cotton producing countries. Ecol Econ 60:186-203 
Damiani M, Núñez M, Roux P et al (2018) Addressing water needs of freshwater ecosystems in life cycle impact assessment of water consumption: state of the art and applicability of ecohydrological approaches to ecosystem quality characterization. Int J Life Cycle Assess 23:2071-2088

Dolganova I, Mikosch N, Berger M et al (2019) The water footprint of european agricultural imports: hotspots in the context of water scarcity. Resources 8:141

Gawel E, Bernsen K (2013) What is wrong with virtual water trading? On the limitations of the virtual water concept. Environ Plan C Gov Policy 31:168-181

go-CAM (2020) Implementing strategic development goals in Coastal Aquifer Management (go-CAM). https://www.tu-braunschweig.de/en/lwi/hywag/forschung-projekte/gocam. Accessed 18 July 2020

GRoW (2020) GRoWnet - water as a global ressource. https://bmbf-grow.de/en. Accessed 18 July 2020

Hanafiah MM, Xenopoulos MA, Pfister S et al (2011) Characterization factors for water consumption and greenhouse gas emissions based on freshwater fish species extinction. Environ SciTechnol 45:5272-5278

Hoekstra AY (2013) The water footprint of modern consumer society. Routledge, Abington

Hoekstra AY (2019) Green-blue water accounting in a soil water balance. Adv Water Resour 129:112-117

Hoekstra AY, Hung PQ (2002) Virtual water trade: a quantification of virtual water flows between nations in relation to International Crop Trade. In: Value of water research report series 11. UNESCO-IHE, Delft

Hoekstra AY, Chapagain AK (2007) Water footprints of nations: water use by people as a function of their consumption pattern. Water Resour Manag 21:35-48

Hoekstra AY, Mekonnen MM (2012) The water footprint of humanity. Proc Natl Acad Sci 109:3232-3237

Hoff H (2011) Background paper for the Bonn 2011 Nexus Conference: THE WATER, ENERGY AND FOOD SECURITY NEXUS. Available online: https://www.water-energy-food.org/uploads/media/ understanding_the_nexus.pdf. Accessed 16 Aug 2019. Stockholm, Sweden

InoCottonGROW (2020) Innovative impulses reducing the water footprint of the global cotton-textile industry towards the UN Sustainable Development Goals. https://www.inocottongrow.net/. Accessed 18 July 2020

ISO 14046 (2014) Water footprint - principles, requirements and guidance. International Organization for Standardization, Geneva

Koellner T, Bonn A, Arnhold S et al (2019) Guidance for assessing interregional ecosystem service flows. Ecol Indic 105:92-106

Lathuillière MJ, Bulle C, Johnson MS (2016) Land Use in LCA: including regionally altered precipitation to quantify ecosystem damage. Environ SciTechnol 50:11769-11778

MedWater (2020) Sustainable use of political and economical relevant water resources in hydraulic, climatic and ecological high-dynamic hard rock aquifers of the mediterranean area. http://grow-medwa ter.de/home/. Accessed 18 July 2020

Mikosch N, Becker R, Schelter L et al (2020) High resolution water scarcity analysis for cotton cultivation areas in Punjab. Pakistan Ecol Indic 109:105852

Mila i Canals L, Chenoweth J, Chapagain A et al (2008) Assessing freshwater use in LCA: part I - inventory modelling and characterisation factors for the main impact pathways. Int J Life Cycle Assess 14:28-42

Motoshita M, Itsubo N, Inaba A (2011) Development of impact factors on damage to health by infectious diseases caused by domestic water scarcity. Int J Life Cycle Assess 16:65-73

Motoshita M, Ono Y, Pfister S et al (2018) Consistent characterisation factors at midpoint and endpoint relevant to agricultural water scarcity arising from freshwater consumption. Int J Life Cycle Assess 23:2276-2287

Nouri H, Chavoshi Borujeni S, Hoekstra AY (2019) The blue water footprint of urban green spaces: an example for Adelaide. Australia Landsc Urban Plan 190:103613

Nouri H, Stokvis B, Galindo A et al (2019) Water scarcity alleviation through water footprint reduction in agriculture: the effect of soil mulching and drip irrigation. Sci Total Environ 653:241-252

Nouri H, Stokvis B, Chavoshi Borujeni S et al (2020) Reduce blue water scarcity and increase nutritional and economic water productivity through changing the cropping pattern in a catchment. J Hydrol 588: 125086

Pfister S, Koehler A, Hellweg S (2009) Assessing the environmental impacts of freshwater consumption in LCA. Environ Sci Technol 43:4098-4104

Pradinaud C, Northey S, Amor B et al (2019) Defining freshwater as a natural resource: a framework linking water use to the area of protection natural resources. Int J Life Cycle Assess 24:960-974

Ridoutt BG, Huang J (2012) Environmental relevance-the key to understanding water footprints. Proc Natl Acad Sci U S A 109:E1424

Schyns JF, Hoekstra AY, Booij MJ et al (2019) Limits to the world's green water resources for food, feed, fiber, timber, and bioenergy. PNAS 116(11):4893-4898. https://www.pnas.org/content/116/11/4893 
Suweis S, Rinaldo A, Maritan A, D'Odorico P (2013) Water-controlled wealth of nations. Proc Natl Acad Sci U S A 110:4230-4233

UN Water (2019) The United Nations World Water development report 2019. Paris, France

van Zelm R, Schipper AM, Rombouts M et al (2011) Implementing groundwater extraction in life cycle impact assessment: characterization factors based on plant species richness for the Netherlands. Environ Sci Technol 45:629-635

Verones F, Saner D, Pfister S et al (2013) Effects of consumptive water use on wetlands of international importance. Environ Sci Technol 47:12248-12257

ViWA (2020) Multiscale monitoring of global water resources and options for their efficient and sustainable use. https://viwa.geographie-muenchen.de/. Accessed 18 July 2020

WANDEL (2020) Water resources as important factor in the energy transition at local and global scale. https ://wandel.cesr.de/en/. Accessed 18 July 2020

WBGU - German Advisory Council on Global Change (2011) World in transition - a social contract for sustainability. Flagship Report. Berlin, Germany

WEF (2020) The global risks report 2020

WELLE (2020) The water footprint of companies: local measures in global supply chains. https://welle.see. tu-berlin.de/. Accessed 18 July 2020

Wichelns D (2015) Virtual water and water footprints: overreaching into the discourse on sustainability, efficiency, and equity. Water Altern 8:396-414

Publisher's Note Springer Nature remains neutral with regard to jurisdictional claims in published maps and institutional affiliations. 